\title{
Performance Evaluation of Coal Logistics Transportation Network Research LI Hongxia ${ }^{1, a}$, HU Xiaofan ${ }^{2, b}$, LI Yan ${ }^{3, c}$
}
${ }^{1}$ Energy Economy and Management Research Center, Xi'an University of Science and Technology Xi'an 710054, China.

${ }^{2}$ Energy Economy and Management Research Center, Xi'an University of Science and Technology Xi'an 710054, China.
${ }^{3}$ Energy Economy and Management Research Center, Xi'an University of Science and Technology Xi'an 710054, China.
a1370452644@qq.com , 406144519@qq.com , ㄷ32058171@qq.com

Keywords: Transportation Network; Coal Logistics; Performance Evaluation.

Abstract: The paper combines with the domestic and foreign research status quo of logistics performance evaluation and coal logistics network, according to the design idea of evaluation system, performance evaluation system for the coal logistics transportation network is established. Based on AHP and fuzzy comprehensive evaluation method of performance evaluation of coal logistics transportation network. Finally the evaluation combined with Ordos coal mine, and according to the evaluation results to find the deficiency, aiming at these disadvantages put forward the counter measures to solve the problem, let it make for the better development.

\section{Introduction}

The background. Coal is one of the most important energy in our country, over $76 \%$ of the total energy production in our country. The coal resources mining because of its convenience, high availability, relatively low cost and mining technical requirements are relatively low, has become the dominant energy industry of our country. However, the current coal logistics transportation network is formed based on the business of coal enterprise dynamic logistics network, coal logistics transportation network in the running process often encounter all sorts of problems, which seriously affected the efficiency of coal transportation. Finding out their advantages and disadvantages, this will be for the future of our country economy development and the sustainable development of coal ind ustry has quite important significance ${ }^{[1]}$.

The theory. Analytic Hierarchy Process (AHP) is a kind of multi-criteria decision-making method, widely used in the analysis and decision-making of complex systems. Using AHP method to determine the evaluation objects needed for the performance evaluation index weight, strong operability, it can be used to evaluate the performance of logistics system; Fuzzy comprehensive evaluation is the comparison of the in fuzzy environment, for related target, to conduct overall evaluation of things affected by many factors, and to make relevant decisions [2]. The fuzziness of the index usually uses the expert evaluation method and questionnaire investigation method to evaluate, subjectivity is stronger, thus giving these to evaluate again after the corresponding weights of evaluation indexes, so as to get closer to the reality of the evaluation results, and is more reasonable.

\section{The Coal Transportation Network}

The present situation of the logistics By coal logistics network for our country's coal conveying direction and the main methods of delivery. Among them, the railway is the main mode of transportation the east west coal shipped its dominant transmission efficiency[3]. But in scale, technology and equipment level of railway lines and transportation service level still have some shortcomings. Railway transport capacity growth lags behind the growth rate of coal production and transportation demand. Although the transportation infrastructure construction has been to speed up the pace, but it is still difficult to meet the increasing of coal demand, the growth of the throughput also slowly, make the coal demand of "south north coal shipped" also difficult to meet. Inland 
waterway transport of coal also has many problems, such as channel level is not high, and blockage of the segment and terminal facilities construction lagging behind. Highway transportation lines a re widely distributed, flexibility is strong, but little bike throughput, energy consumption and transportation cost is larger, apply only to the coal in a certain range to short delivery.

The research purpose. China's coal transportation channels need to strengthen the infrastructure of reasonable planning and construction, improve the management system, and make the transportation system of computer matching. Study abroad in the process of logistics development, found that the United States, Japan, Europe and other developed countries attach great importance to the construction of logistics infrastructure, its logistics system is based on information technology as the core, and showed the trend of the development of intellectualization and cross combination. At the beginning of the 20th century, China's logistics industry has been rapid development, and to reduce costs, increase profits, improve the operation efficiency and service level, etc, to get attention of the coal enterprise, to speed up the development of coal logistics industry.

\section{The Modeling}

The construction of Pe rformance evaluation system. Coal logistics transportation network performance can be evaluated by the fuzzy analytic hierarchy process. This paper listed the factors affecting coal logistics transportation network, and then designed the security questionnaire to fuzzy evaluation of various factors. Based on Index hierarchical structure chart, and combined with the practical situation of the performance evaluation of Ordos coal mine, built the Ordos coal logistics transportation network performance evaluation index system. It establishes an index system of classification, such as the target layer A, criterion layer B and specific index layer C. According to the evaluation index system of the basic relationship, a Hierarchical structure model was built.

Construction of evaluation set. This paper will set evaluation $V=\{V P\}, p=1,2,3$. Respectively represent the negative, moderate and positive. Determine the recognition evaluation index set: First index $A=\{A\}$; Second index $B=\{B i\} \quad i=1,2,3,4$; Third index $C=\{C j\} j=1,2$, $3 \ldots .10 ; \mathrm{B} 1=\{\mathrm{C} 1, \mathrm{C} 2, \mathrm{C} 3, \mathrm{C} 4\} ; \mathrm{B} 2=\{\mathrm{C} 5, \mathrm{C} 6\} ; \mathrm{B} 3=\{\mathrm{C} 7, \mathrm{C} 8\} ; \mathrm{B} 4=\{\mathrm{C} 9, \mathrm{C} 10\}$. It is coal logistics transportation network performance, For example: B1 is financial capacity, B2 is network capacity, B3 is network operation safety, B4 is information service ability; C1 is profitability, C2 is debt paying ability , C3 is operation ability, C4 is development ability, C5 is transport efficiency, C6 is service level, C7 is node security, C8 is network security, C9 is information transmission capacity, $\mathrm{C} 10$ is customer information service.

Setting up the weight by AHP method. In an evaluation scheme, the degree of various factors is different. Reflect the weight of each factor to the importance of the sets is $\mathrm{W}=(\mathrm{w} 1, \mathrm{w} 2, \ldots, \mathrm{wn})$. In this paper, the effective recovery was 50 copies questionnaires, the questionnaire survey results on the relative importance between evaluation ability indexes.

Construct two comparative judgment matrix $A$

$$
A=\left[\begin{array}{cccc}
\alpha_{11} & \alpha_{12} & \ldots & \alpha_{1 n} \\
\alpha_{21} & \alpha_{12} & \ldots & \alpha_{2 n} \\
\ldots & \ldots & \ldots & \ldots \\
\alpha_{n 1} & \alpha_{n 2} & \ldots & \alpha_{n n}
\end{array}\right]
$$

Note: $\alpha_{i j}>0, \quad \alpha_{i j}=1 / \alpha_{j i}, \quad \alpha_{i j}=1 ;(i, j=1,2, \ldots n)$

Calculating weight vector. $\mathrm{W}=\left(\mathrm{w}_{1}, \mathrm{w}_{2}, \ldots, \mathrm{w}_{\mathrm{n}}\right)$. The calculation method of $\mathrm{W}$ can adopt method of approximate calculation of the root (Limited space, the process briefly). By $A W=\lambda_{\max } W$ to eigenvector $\mathrm{W}$, then normalized, normalized after the characteristics of the vector $\mathrm{W}$ as evaluation index weight vector. Eigen value of maximum: 


$$
\lambda_{\max }=\frac{\sqrt[n]{\prod_{i=1}^{n} \alpha_{i j}}}{\prod_{i=1}^{n} \sqrt[n]{\prod_{j=1}^{n} \alpha_{i j}}},(\mathrm{i}, \mathrm{j}=1,2,3, \ldots, \mathrm{n})
$$

The consistency check of matrix A, The steps are as follows:

Index C.I. : C.I. $=\frac{\lambda \max -n}{n-1} \quad \mathrm{~N}$ is the order to judgment matrix.

Calculate the average random consistency index R.I., R.I. is the result through many tim es after repeated random judgment matrix calculation and take arithmetic average. Consiste ncyIndex C.R.:C.R.= C.I/ R.I. As a general rule, we think the consistency of judgment matr ix is acceptable when C.R. $<0.1$.

\section{Empirical Analysis}

Ordos city has rich coal resources, Dongsheng coalfield and ZhuoZiShan coalfield established coal reserves of 149.6 billion tons of coal, the mining of coal reserves of about 17.5 billion tons, planning and undeveloped reserves of 49.8 billion tons, covering relatively deep Dongsheng field, about 57.1 billion tons .It is estimate that about 1 trillion tons of reserves in the future.

Obtain evaluation data. This paper utilize questionnaire survey form obtain the membership data. Through questionnaire data statistics and the weight $\mathrm{B}$ layer, it is concluded that $\mathrm{C}$ layer of each concrete index compared with the criterion layer B and target layer A weight, and then get the fuzzy comprehensive evaluation of membership degree matrix. By integrating, the following data are obtained: Membership of B layer $=\{0.6207,0.1600,0.2400,0.1200\}$; Membership of C layer relative to B layer $=\{0.5009 ; 0.3806 ; 0.4516 ; 0.1602 ; 0.5220 ; 0.1584 ; 0.2889 ; 0.1179 ; 0.5695 ; 0.0974\}$;

Membership of $\mathrm{C}$ layer relative to A layer $=$ $\{0.3109 ; 0.2362 ; 0.2803 ; 0.0994 ; 0.0835 ; 0.0253 ; 0.0693 ; 0.0283 ; 0.0683 ; 0.0117\}$.

Fuzzy comprehensive evaluation. Level of comprehensive evaluation result $B=W \times R, W$ is index level weight, $R$ is Fuzzy comprehensive evaluation membership degree matrix:

$$
\begin{aligned}
& W_{1}=\left(\begin{array}{llll}
0.5009 & 0.3806 & 0.4516 & 0.1602
\end{array}\right) \quad W_{2}=\left(\begin{array}{llll}
502 & 20058
\end{array}\right) \quad W_{3}=\left(\begin{array}{lll}
0.2889 & 0.1179
\end{array}\right) \quad W_{4}=\left(\begin{array}{lll}
0.5695 & 0.0974
\end{array}\right) \\
& R_{1}=\left(\begin{array}{ccc}
0 & 0.16 & 0.56 \\
0.10 & 0 & 0.50 \\
0.25 & 0.25 & 0.35 \\
0 & 0.30 & 0.28
\end{array}\right) \\
& R_{2}=\left(\begin{array}{lll}
0.15 & 0.20 & 0.16 \\
0.24 & 0.28 & 0.22
\end{array}\right) \\
& R_{3}=\left(\begin{array}{lll}
0.10 & 0.18 & 0.26 \\
0.20 & 0.30 & 0.26
\end{array}\right) \\
& R_{4}=\left(\begin{array}{ccc}
0 & 0.18 & 0.32 \\
0.20 & 0.14 & 0.54
\end{array}\right) \\
& B_{1}=\left(\begin{array}{lll}
0.151 & 0.2411 & 0.6737
\end{array}\right) \\
& B_{2}=\left(\begin{array}{lll}
0.1163 & 0.5479 & 0.1184
\end{array}\right) \\
& B_{3}=\left(\begin{array}{lll}
0.0525 & 0.0834 & 0.1058
\end{array}\right) \\
& B_{4}=\left(\begin{array}{lll}
0.0195 & 0.1161 & 0.2348
\end{array}\right)
\end{aligned}
$$

Table 1. The first level evaluation results

\begin{tabular}{lccc}
\hline B & \multicolumn{3}{c}{ Evaluation result } \\
\hline $\mathrm{B}_{1}$ & 0.151 & 0.2411 & 0.6737 \\
$\mathrm{~B}_{2}$ & 0.1163 & 0.5479 & 0.1184 \\
$\mathrm{~B}_{3}$ & 0.0525 & 0.0834 & 0.1058 \\
$\mathrm{~B}_{4}$ & 0.0195 & 0.1161 & 0.2348 \\
\hline
\end{tabular}

As we can see from the table, financial capacity, network operations security, information service ability is good, the network capacity is generally.

2) Second class comprehensive evaluation Multiply by W and R, the fuzzy comprehensive evaluation set of secondary indicators.Fuzzy evaluation matrix: 


$$
\begin{aligned}
& R=\left(\begin{array}{ccc}
0.151 & 0.2411 & 0.6737 \\
0.1163 & 0.5479 & 0.1184 \\
0.0525 & 0.0834 & 0.1058 \\
0.0195 & 0.1161 & 0.2348
\end{array}\right) \\
& B=W \times R=\left(\begin{array}{ccc}
0.151 & 0.2411 & 0.6737 \\
0.1163 & 0.5479 & 0.1184 \\
0.0525 & 0.0834 & 0.1058 \\
0.0195 & 0.1161 & 0.2348
\end{array}\right)\left(\begin{array}{llll}
0.6207 & 0.16 & 0.24 & 0.12
\end{array}\right)=\left(\begin{array}{llll}
0.1159 & 0.2713 & 0.4907
\end{array}\right) \\
& \text { Table 2. Second- level evaluation results }
\end{aligned}
$$

\begin{tabular}{|c|c|c|c|}
\hline \multirow{2}{*}{ Evaluation } & \multicolumn{3}{|c|}{ Evaluation result } \\
\hline & negative & moderate & positive \\
\hline & 0.1159 & 0.2713 & 0.4907 \\
\hline
\end{tabular}

We can see that Ordos's coal logistics transportation network performance is good. But from all the layers of the metrics, financial capacity, logistics network operation safety, logistics information service ability in general is good, and logistics network operation ability is general. In financial capacity good profit ability, debt paying ability, operation ability, development ability is general. Logistics nodes in network operation safety security is good. Logistics information service capacity, information transmission capacity, customer information service are all good. In the logistics network capacity, transport efficiency and service level.

\section{Suggestions}

According to the evaluation conclusion, the relevant Suggestions to improve our ability from it development, logistics network security, logistics efficiency and logistics information service level these aspects, as follows:

Firstly, from the point of development ability, strict supervision of coal quality, raising the price of coal; In order to strengthen the management of marketing, expand market share, improve market share; Audit cost expense strictly, strengthening the cost control.

Secondly, from the point of logistics network security, to the enterprise's internal and external network isolation and access control, auditing and monitoring, network backup system ${ }^{[4]}$.

Thirdly, from the point of logistics transport efficiency, should combine the distribution of the Ordos coal mining area, road network status and planning, all information such as user distribution and coal demand, establish the network plan of site selection of each node, and the Ordos area to evaluate logistics network nodes location decision, it is a reasonable number of nodes.

Fourthly, from the point of logistics information service level, promote and implement of fine management, actively establish a clear duty, administrative rights clear, rights and responsibilities, scientific, standardized, simple and efficient, mutual integration, security as a whole, dynamic management control system and improve the execution of enterprise management.

\section{Conclusion}

Coal in recent decades, due to its abundant resources to occupy the main energy consumption status in China, but because our country's coal distribution and economic development level is not corresponding to the coal production areas away from the coal demand in the market, which increased the pressure of long distance coal transportation, involve a series of complex problem. Research of coal logistics transportation network performance, the sustainable development of economy in China is of great significance ${ }^{[5]}$. The research content of this paper focuses on the following aspects:

Firstly, through the summary of coal logistics, performance evaluation, the AHP and fuzzy comprehensive evaluation method of information literature, to summarize the basic structure of logistics network, due to the complexity of coal logistics network as a kind of special logistics 
network system. Generally, the management mode of logistics network system has does not apply to the coal logistics network system, this paper established the performance evaluation index of coal logistics network system, directly applied in the integration of the Ordos coal mine.

Secondly, in view of the current problems existing in the coal logistics transportation network, Using AHP and fuzzy comprehensive evaluation method, construct the performance evaluation of coal logistics transportation network system, and meeting the needs of performance evaluation of Ordos coal transportation network related indicators. According to the established system to analyze it. On the basis of the results of the analysis, put forward suggestions for improvement of Ordos coal logistics transportation network.

\section{Acknowledgment}

Supported by Project of Shaanxi Provincial Department of Education (11JK0061; 13JZ029; 14JK1445); Soft Science Project of Shaanxi Provincial Department of Science and Technology (2011KRM41); and Xi'an University Of Science and Technology (JG1209;2013SY01;2014SX07); National Natural Science Foundation (71271169, 71273208), Ph.D. Programs Foundation of Ministry of Education of China (20126121110004, 20116121110002)

\section{Reference}

[1] Zhao Luhua, Cao Qinggui, Yuan Yuli. The coal logistics transport network risk assess ment and countermeasures research in China [J]. Journal of safety science and technology of China, 2012, (8) : 92-97.

[2] Xia Caiyun. AHP and fuzzy comprehensive evaluation method in the application of logistics enterprise supplier selection research [J]. Road transport and logistics, 2011, (7) : 128-131 (2): 357-361.

[3] Huang Zhijian, Shi Chunfen. Our country coal logistics research review [J]. Journal of logistics engineering and management, 2011 (1) : 12-14.

[4] Zhao Jing, Wang Tao, Wang Xi-lian. Interest relationship for development of energy chemical base [J]. Journal of Xi'an University Science and Technology, 2008, 28

[5] Guan Xiaojun. Performance evaluation of coal logistics transportation network study [J]. Journal of logistics technology, 2011, 30 (8) : 36 -38. 